\title{
ALGUMAS REFLEXÕES SOBRE EDUCAÇÃO SEXUAL E ESTUDOS DE GÊNERO NO TRABALHO DE EDUCADORES DO CICLO II E ENSINO MÉDIO
}

\author{
Karla Cristina Vicentini de ARAUJO ${ }^{1}$ \\ Viviane Oliveira AUGUSTO \\ Paulo Rennes Marçal RIBEIRO ${ }^{3}$
}

\begin{abstract}
RESUMO: A educação sexual é um processo constante e contínuo que objetiva desenvolver a autonomia nas questões referentes à sexualidade. As relações de gênero são marcadas por desigualdades, submissão e obediências determinadas e construídas histórica e culturalmente, constituindo relações de poder. Na escola, estes processos socioculturais se repetem a partir das atitudes e comportamentos que podem ser observados em professores e alunos, portanto a escola se torna um espaço propício ao desenvolvimento de ações educativas na esfera da sexualidade. O objetivo deste trabalho, então, foi analisar possibilidades e verificar a importância de se trabalhar questões referentes à educação sexual e gênero no ambiente escolar. O trabalho foi realizado em dois encontros, sendo utilizados como instrumentos, anotações e informações obtidas pelos pesquisadores. Pudemos perceber que a orientação sexual no cotidiano escolar ocorre de maneira escassa e informal, os professores não têm formação para atuar, e quando se manifestam geralmente suas posturas e opiniões eram carregadas de preconceitos e estereótipos. No entanto, sua participação nos encontros foi positiva e foi possível promover a reflexão sobre várias questões referentes à sexualidade e gênero. Os educadores foram capazes de refletir criticamente sobre a importância da educação sexual e a expressão da sexualidade do ser humano, identificando e questionando valores, estereótipos, preconceitos e crenças culturalmente inseridas nas vidas destes profissionais.
\end{abstract}

PALAVRAS-CHAVE: Educação Sexual. Sexualidade. Gênero. Educação. Cotidiano Escolar.

\section{Introdução}

Os seres humanos se inserem no mundo a partir dos seus corpos sexuados e com ele se relacionam por meio de construções sociais, culturais e históricas. Sendo seres sexuados e sexuais, inserem a sexualidade em todos os processos de vida, não sendo possível qualquer ação desvinculada dessa sexualidade. Não há como dela separar o corpo, as atitudes e a afetividade. No entanto, tamanha proximidade provoca atritos, pois a cultura reprime manifestações sexuais que são contrárias às normas e padrões construídos historicamente e

\footnotetext{
${ }^{1}$ Aluna especial de Psicologia da Educação. UNESP - Universidade Estadual Paulista. Faculdade de Ciências e Letras - Pós-Graduação em Psicologia da Educação - Núcleo de Estudos da Sexualidade. Araraquara - SP Brasil. 14800-901 - karlavicentini@ig.com.br

${ }^{2}$ UNESP - Universidade Estadual Paulista. Faculdade de Ciências e Letras - Núcleo de Estudos da Sexualidade. Araraquara - SP - Brasil. 14800-901- vivianeoaugusto@gmail.com

${ }^{3}$ UNESP - Universidade Estadual Paulista. Faculdade de Ciências e Letras - Departamento de Psicologia da Educação - Programa de Pós-Graduação em Educação Escolar.. Araraquara - SP. - Brasil. 14800-901 paulorennes@fclar.unesp.br
} 
em conformidade com tabus e preconceitos religiosos e sociais. Os indivíduos são sexualmente educados desde o nascimento, aprendendo quais são as atitudes e comportamentos socialmente esperados e posicionando-se diante de contínuos conflitos entre o desejo, a repressão e a culpa. A educação sexual quando saudável e libertadora é um processo constante e contínuo que objetiva desenvolver a autonomia nas questões referentes à sexualidade. Quando é patológica e castradora limita as ações, causa sofrimento psíquico e desprazer. No caso das relações de gênero, estas são marcadas por desigualdades, submissão e obediências igualmente determinadas e construídas histórica e culturalmente, constituindo relações de poder. No cotidiano recebemos várias mensagens, através dos meios de comunicação sobre regras e valores que nos incentivam e direcionam o modo de expressar a sexualidade e compreender o ser humano, muitas vezes de forma inadequada mostrando preconceitos e tabus sobre gênero e sexualidade, outras vezes de forma educativa, promovendo reflexões. Na escola, estes processos socio-culturais se repetem a partir das atitudes e comportamentos que podem ser observados em professores e alunos, portanto a escola se torna um espaço propício ao desenvolvimento de ações educativas na esfera da sexualidade.

Michel Foucault (1997 apud RIBEIRO; SOUZA; SOUZA, 2004, p.112) explica que

[...] a sexualidade é o nome que pode ser dado a um dispositivo histórico: "não à realidade subterrânea que se apreende com dificuldade, mas à grande rede da superfície em que a estimulação dos corpos, a intensificação dos prazeres, a incitação ao discurso, a formação dos conhecimentos, o reforço dos controles e das resistências encadeiam-se uns aos outros, segundo algumas estratégias de saber e de poder.

E Joan Scott (1995, p.71) fundamenta suas teorias nos seguintes princípios:

As relações de gênero são marcadas por desigualdades, hierarquias e obediências, sendo relações de poder. Elas possuem uma dinâmica própria, se articulando através de outras formas de dominação e desigualdades sociais, como raça, etnia, classe, etc. Sendo legitimada socialmente, se constitui em construções. Essa perspectiva permite entender as relações sociais entre homens e mulheres, o que pressupõe modificações e conservações, desconstruções e reconstrução de elementos simbólicos, imagens, práticas, comportamentos, normas, valores e representações. O estudo da história social é reforçado pela categoria de gênero, ao mostrar que todo tipo de relação não se constitui em realidades naturais. De acordo com as necessidades concretas que o ser humano necessita, ele elabora combinações e arranjos para a sua vida. Os conflitos, negociações, tensões e alianças, estão presentes seja na luta das mulheres pala ampliação e busca do poder, ou na manutenção dos poderes masculinos. 
A sexualidade faz parte da vida e da condição humana. Todas as sociedades apresentam valores culturais sobre educação sexual, que são incorporados e reproduzidos em cada geração e cada contexto. É algo além do sexo, órgãos sexuais, das práticas sexuais, afetividade e do relacionamento, é um conceito amplo que extrapola a genitalidade.

Sexualidade e educação sexual são temas que ainda não estão bem resolvidos e definidos nos programa desenvolvidos pelo Ministério da Educação e no cotidiano das escolas brasileiras. Quando estes programas são implantados, a prática acaba ficando destorcida, não englobando a essência e atingindo seu real objetivo. Isso ocorre por que o contexto escolar não se apresenta bem estruturado para lidar com as questões de várias origens, que surgem de acordo com o amadurecimento físico e psicológico dos educandos.

O auxílio de profissionais formados e capacitados para exercer a função de suporte pedagógico para o enfrentamento dos problemas originados no convívio cotidiano dos alunos, é importante porque surge da dificuldade apresentada ao trabalhar com temas sobre educação sexual e gênero, que por falta de aprofundamento teórico, acaba utilizando conceitos de senso comum e vivências, demonstrando uma concepção de falha no ensino.

É importante que instituições educacionais, governamentais e a própria população se conscientizem da importância da incorporação da educação sexual como um fator fundamental a ser trabalhado e desenvolvido adequadamente. Para que se possa aplicar no cotidiano escolar, sendo um fator de desenvolvimento e da organização social, pois a educação é garantia de cidadania e liberdade.

A educação sexual é um processo constante que pode ocorrer intencionalmente ou não. Ela pode ocorrer de forma inadequada, apresentando caráter autoritário, limitado, conservador, repressor, ou de forma adequada proporcionando reflexões, críticas construtivas e caráter emancipátorio.

Assim,

[...] podemos dizer que onde existe diferenciação - ou seja, identidade e diferença - aí está presente o poder. A diferenciação é o processo central pelo qual a identidade e a diferença são produzidas. Há, entretanto, uma série de outros processos que traduzem essa diferenciação ou com ela guardam uma estreita relação. São outras tantas marcas da presença do poder: incluir/excluir ("estes pertencem, aqueles não"); demarcar fronteiras ("nós e eles”); classificar ("bons e maus"; "puros e impuros"; "desenvolvidos e primitivos"; "racionais e irracionais"); normalizar ("nós somos normais; eles são normais”). (SILVA, 2000, p.81-82). 
A abordagem da educação sexual emancipatória é percebida como algo intencional para promover intervenções qualitativas no processo educacional que ocorre frequentemente nas relações sociais. É uma busca da reconstrução consciente de um saber amplo e universal sobre a liberdade sexual do ser humano. Ela se mostra como uma temática fundamental que busca posturas fundamentais para o desenvolvimento da sexualidade, promovendo o direito para todos. Ela pressupõe desvendar modelos e projetar novos caminhos em busca de algo melhor para a sociedade em que vivemos, respeitando a diversidade cultural, através de uma nova compreensão da dimensão da sexualidade sendo parte indissociável da vivencia humana no processo de educação.

A educação sexual, denominada orientação sexual por vários autores e pelos PCNs, deve ser intencional, estruturada e sistematizada, para fornecer adequadamente informações sobre sexualidade. Sua importância é explicitada na seguinte citação:

Ao não se garantir espaços e tempos específicos para tratar sexualidade, pode se colaborar pelo fortalecimento de concepções que supõem a sexualidade como assunto secundário, que não tem o devido valor, como status inferior a outras disciplinas, reforçando o caráter marginal que historicamente tem sido atribuído à sexualidade. (CARRADORE; RIBEIRO, 2006, p.100).

A educação, antropologia, a psicologia, e seus afins, a sociologia e a história, apresentam instrumentos e capacidade de pesquisa, debate, discussões, reflexões e intervenções em processos educativos que possam contribuir para possibilitar a compressão da sexualidade, educação sexual e gênero. Algo necessário, considerando a sociedade sendo passível de mudanças, para melhorar a qualidade de vida.

A sexualidade deveria deixar de ser vista somente como um objeto de estudo das várias áreas do saber, para ser compreendida como uma questão estrutural e parte indissociável do cotidiano escolar e do contexto social em que estamos inseridos. Essa negação de que a sexualidade esteja presente na escola e faça parte do cotidiano dos professores, Foucault (1997) diz que desde a época vitoriana a sexualidade ficou limitada no interior das casas, especificamente no quarto dos pais, onde sua função era unicamente a de reprodução. E os que não se enquadrasse a essas normas e regras eram vistos e apontados como anormais, e pagariam as sanções que o estereótipo lhe causaria. Encontramos essa prática nos tempos atuais, quando os professores repreendem seus alunos, alegando que ali não é o momento para tratar desse assunto. Além de repreender e coagir o aluno quando ele traz à tona a sexualidade, se esse aluno insistir na questão é classificado, estereotipado e 
muitas vezes encaminhando para outras instâncias e profissionais, pois ele foge as regras e normas instituídas.

Os educadores necessitam de auxilio para melhorar a qualidade da educação sexual no cotidiano da escola, pois a maioria das formações universitária não promovem formação específica para este foco. Como os alunos manifestam a expressão da própria sexualidade no cotidiano escolar, o que indica a necessidade de conhecimentos, habilidades e práticas, para saber lidar e aproveitar as oportunidades apresentadas e vivenciadas, com a finalidade de promover a educação sexual a partir dessas situações. Pois este tem que ser o papel do educador:

[...] consideramos que a escola deve preparar para o viver bem, faz parte do viver bem saber lidar com as múltiplas escolhas, que se nos apresentam no campo da sexualidade [...] [...] A escola deve sim, assumir a responsabilidade para contribuir para a formação de crianças e adolescentes para que estes possam ser sujeitos de sua própria sexualidade e de sua própria vida. (CARRADORE; RIBEIRO, 2006, p.95).

Para obter resultados favoráveis no processo formativo, além de conhecimentos específicos, é necessário trabalhar atitudes, sendo a principal, o reconhecimento da necessidade da inserção da educação sexual fazendo parte da tarefa da escola, enquanto agente provedor de educação. É importante a conscientização da importância de desenvolver a inserção da temática abordada, para que se possam ser trabalhados adequadamente temas relacionados à educação sexual, sexualidade e gênero. Favorecer a reflexão sobre esta prática, estudar o assunto e discutir em grupo é necessário para que o resultado obtido seja favorável.

A educação sexual tem como intenção desenvolver a autonomia nas questões referentes à sexualidade. É necessário abrir oportunidades para que exista um processo de crescimento e desenvolvimento dos educadores, na busca de um constante aperfeiçoamento e refletindo assim para a existência de uma sociedade menos repressora e mais igualitária.

\section{Objetivos e aspectos metodológicos}

O principal objetivo deste trabalho foi promover nos educadores a reflexão a partir de fundamentos teóricos sobre a importância de trabalhar questões referentes à sexualidade e gênero com os educandos. Também pensamos em analisar e refletir com o grupo de sujeitos o cotidiano vivido por professores no universo escolar, identificando as questões que surgem mais comumente na escola e como eles que abordam gênero e sexualidade, levando-os a refletir sobre a importância da categoria social gênero na modelação das relações individuais e 
dos comportamentos, nos variados contextos de vida. O trabalho com os professores possibilitou proporcionar uma discussão sobre o caráter persuasivo dos estereótipos de sexualidade e gênero nas percepções que os indivíduos fazem de si próprios; analisar situações vivenciadas no cotidiano escolar, nas quais as desigualdades de gênero são visíveis; identificar, comportamentos e atitudes pedagógicas passíveis de contribuir para uma educação que perpetue, implícita ou explicitamente, as visões tradicionais sobre as características e as competências típicas de cada um dos sexos, habitualmente conducentes a situações de discriminação.

Esperamos que os educadores sejam capazes de refletir criticamente sobre a importância da educação sexual e a expressão da sexualidade do ser humano; que possam identificar alguns aspectos dos estereótipos de gênero que traduzem a atuação do homem e das mulheres na vida cotidiana; e que, enquanto profissionais, sejam capazes de questionar práticas e crenças estabelecidas em diferentes contextos formais, e não formais de aprendizagem e de interação social. Assim, tendo em vista a promoção de uma melhoria na qualidade do ensino e a inserção da educação sexual e a liberdade de expressão da sexualidade, estaremos ajudando a construir uma sociedade mais permeável a estereótipos.

A opção em trabalhar com professores, a questão da educação sexual e gênero deriva da dificuldade que estes apresentam ao trabalhar com tais temas, que por falta de aprofundamento teórico, acabam utilizando conceitos de senso comum, que demonstra uma concepção de inferioridade intelectual, física, social e cultural das diversas expressões da sexualidade e de gênero.

Os sujeitos participantes desta pesquisa são 12 professores do Ciclo II e Ensino Médio da rede pública de ensino de uma cidade do interior do estado de São Paulo.

Como instrumento, foi utilizado no processo de investigação, anotações e informações obtidas nos encontros de forma que com o uso destes dados obtidos não se perca nenhum fator importante que faça parte da investigação e facilite a análise dos dados coletados.

Para fornecer as informações necessárias, levando às reflexões das temáticas trabalhadas, foi utilizado para a apresentação, um data show e um computador para projeção de duas imagens trabalhadas. A primeira é um menino frente ao espelho, calçando um sapato feminino de salto alto, vendo seu reflexo no espelho com envoltório rosa no seu corpo, com a frase: “Construindo Identidades”. A segunda figura apresenta a frase: "Respeito, uma vida sem violência é direito de todos”, com os símbolos de três formas de relacionamento: homossexual (duas pessoas juntas, do sexo masculino e duas pessoas juntas do sexo 
feminino), e um casal heterossexual (homem e mulher). E cópias impressa do texto: "Gênero: Uma Categoria Útil para Análise Histórica” da Joan Scott.

Como estratégia de análise, observamos a narrativa dos educadores, ao visualizarem as figuras exibidas e ao contarem sobre suas vivencias relacionadas ao tema trabalhado, pois através da narrativa e do processo de escutar e contar história, os indivíduos constroem os sentidos tanto de si como de suas vivencias. Pois nossas falas representam as práticas sócias e rede de discurso que estamos inseridos.

O projeto foi executado em dois encontros com intervalo de sete dias entre ambos.

No primeiro encontro foi realizada a apresentação do projeto para os educadores e introduzido os temas que seriam trabalhados com eles. Na seqüência foram projetadas imagens referentes a gênero e sexualidade para promover uma discussão e reflexão sobre a temática, ligando as experiências vivenciadas no cotidiano escolar dos professores. Ao término deste encontro foi entregue aos professores o texto: "Gênero: Uma Categoria Útil para Análise Histórica” da Joan Scott, para que fosse realizada a leitura prévia deste, para o próximo encontro. No segundo encontro, através da leitura prévia realizada pelos professores sobre o texto e as reflexões e discussões que foi despertado através do texto, foram trabalhadas questões trazidas pelos professores, para facilitar o entendimento e a reflexão sobre o conceito principal que o texto aborda, entregamos a eles um resumo impresso com as principais idéias de Joan Scott, facilitando para englobar junto às imagens apresentadas no primeiro encontro e as práticas cotidianas vivenciadas.

Como resultado foi obtido no primeiro encontro com os professores durante a projeção das imagens referentes a gênero e sexualidade, eles permaneceram calados, apenas atentos ao que estava sendo exposto, posteriormente no momento de discussão e reflexão das imagens, onde cada um expressou seus próprios conceitos sobre as imagens, houve discussão onde cada um argumentou vários pontos de vistas, sendo que predominou conceitos estereotipados e carregados de preconceito.

Falas do professores ao visualizar as imagens:

"Que horror”; “Credo”; “Isso não pode”; "Nossa que difícil trabalhar com uma coisa dessa!”; “Se eu visse não saberia o que fazer”;” Complicado, hein”, “ Nossa o menino ta num mundo rosa”; "É mais tem que ser liberal”; “É difícil, mas acho que isso ta certo”; “ Precisamos respeitar né”; “Ele não tem culpa de ser assim”; “ Coitado do pai”; “Que mundo nós estamos",...

No segundo encontro, após a leitura prévia realizada por alguns educadores, como foi orientado no encontro anterior. Para facilitar o entendimento e a reflexão sobre o conceito 
principal que o texto aborda, entregamos a eles um resumo impresso com as principais idéias de Joan Scott. Com isso os colocamos em contato com teorias, promovendo a reflexão do conceito de gênero, para que facilite a compreensão das temáticas de sexualidade, gênero e educação sexual, para serem trabalhadas no cotidiano destes profissionais. Encerramos o encontro gerando uma reflexão sobre as imagens, a vivência no cotidiano escolar e com embasamento teórico da leitura do texto realizado, que foram apresentados no primeiro encontro.

Por meio da análise dos resultados apresentados anteriormente, mediante a análise das falas dos educadores e de acordo com a apresentação das figuras utilizadas, podemos perceber que a hipótese apresentada foi comprovada, porém notamos que na postura deles diante a presença de atividades de reflexão a princípio foram carregadas de preconceitos e estereótipos, porém conseguimos promover a reflexão sobre várias questões referentes à sexualidade vivenciadas no cotidiano deles e da escola.

Percebemos que na representação das imagens para os educadores, a princípio se mantiveram neutros, porém sequencialmente se manifestaram trazendo em suas falas valores e conceitos inseridos culturalmente. Posteriormente ao se depararem com a segunda imagem, percebemos que conseguimos promover a reflexão sobre estes valores e conceitos que estavam inseridos. Assim podendo proporcionar uma reflexão através da fala de suas próprias experiências e ouvindo a dos colegas, conseguindo perceber novas possibilidades de reações, intervenções e orientações mais apropriadas, com uma nova visão diante estes conceitos estereotipados.

Na prática cotidiana da educação sexual ocorre de uma forma muito escassa, deixando de trabalhar conceitos importantes para serem acrescentados no cotidiano escolar. E isto ocorre pela falta de formação e de habilidades que os professores possuem, portanto apresentam dificuldade em trabalhar questões referentes à sexualidade.

Através dos encontros conseguimos promover reflexões sobre a importância de trabalhar sexualidade sendo um instrumento para auxílio do trabalho com os alunos no cotidiano escolar.

Concluímos que este estudo pretendeu verificar se era possível promover a reflexão sobre educação sexual e gênero no trabalho de educadores do ciclo II e ensino médio, a partir da análise de suas falas, em encontros promovidos para favorecer a reflexão e construção de novos conceitos sobre sexualidade, educação sexual e gênero. Comprovamos a hipótese de que educadores seriam capazes de refletir criticamente sobre a importância da educação sexual e a expressão da sexualidade do ser humano, identificando aspectos apresentados nos 
encontros como destaque, os valores, estereótipos, preconceitos e crenças culturalmente inseridas nas vidas destes profissionais.

A escolha da temática apresentada neste trabalho decorre do interesse por uma aproximação maior da teoria sobre gênero, sexualidade e educação sexual enquanto instrumentos de trabalhado para uma atuação favorável diante o contexto escolar, pois o desafio de romper o esquema binário, em que se encontra o masculino e o feminino construídos historicamente e inserido culturalmente, se opondo um ao outro, tem sido desafiante no que se propõe a desmontar um esquema numa lógica patriarcal que dificulta a percepção e construção de mundo de outras formas, diante a educação sexual. Os estudos de autores que abordam a temática relacionada a gênero e educação sexual se apropriam de teorizações relacionadas à desconstrução, para o qual o as idéias e princípios expressados pela hierarquização de pares opostos, são pensados através das relações de gênero, inseridas como objeto de estudo no contexto educacional. Essa proposta é a de desmontar a visão tradicional de trabalho com educação sexual, evidenciando que estas são construídas historicamente, propondo a mudança e promovendo reflexões para que existam novas visibilidades e formas de lidar com o ser humano através da educação sexual. A desconstrução da polaridade tradicional masculino e feminino é importante para desmontar a lógica binária que rege outros pares de conceitos a ela articulados. A classe, etnia, religião, idade, etc., são elementos que atravessam unidades, transformando em múltiplo o sujeito masculino ou feminino eu é visto singularmente.

Espera-se que essa pesquisa tenha contribuído de forma parcimoniosa para a compreensão do funcionamento da dinâmica da transmissão do saber, e das formas de atuação diante situações cotidianas e vivências no contexto escolar.

Por fim, acreditamos ser relevante o desenvolvimento de pesquisas futuras que possam superar as limitações desta e aprofundar a compreensão da temática abordada referente à educação sexual e na influência da sociedade repressora que vivemos atualmente, e que acreditamos que possa ser passível a mudanças, transformando conceitos e valores inseridos culturalmente de forma negativa, assim como preconceitos e estereótipos de forma que isso melhore a qualidade de vida de todos. Verificando que a importância de se atentar no processo de desconstrução, da visão de gênero e educação sexual, construída e inserida culturalmente, para o fato de que o oposto da igualdade é a desigualdade, ao invés da diferença. 


\title{
A CONTRIBUTION AND REFLECTION ABOUT SEXUAL EDUCATION AND GENDER IN WORK OF TEACHERS OF SECOND CYCLE AND HIGH SCHOOL
}

\begin{abstract}
Sexual education is a constant process, having as intention to develop the autonomy on questions referring to sexuality. Gender relations are marked by inequalities, submission and obedience and certain historically and culturally constructed, constituting power relations. At school, these socio-cultural processes are repeated from the attitudes and behaviors that can be observed in teachers and students, so the school becomes a proper place for the development of educational activities in the sphere of sexuality. This papers objective is to analyze possibility and verify the importance of working on questions referring to sexual education and gender in school environment. The work was done in two meetings, being based in information we got by researchers. We can realize that the sexual orientation on school everyday occurs due the lack of teacher's training and skills, the teachers aren't training to work, and usually manifest posture and opinions were full of prejudice and stereotypes. Their participation in the meetings was positive and could promote reflections on questions of sexuality and gender. The educators were able to critically reflect about the importance of sexual education and the sexuality expression oh the human being, identifying and questions values, stereotypes, the prejudice and the beliefs culturally inserted in the life of these professionals.
\end{abstract}

KEYWORDS: Sexual education. Sexuality.Gender. Education. School Everyday.

\section{REFERÊNCIAS}

FOUCALT, M. História da sexualidade: a vontade de saber. 4.ed. Rio de Janeiro: Graal, 1997. v.1.

RIBEIRO, P. R. C.; SOUZA, N. G. S.; SOUZA, D. O. Sexualidade na sala de aula: pedagogias escolares de professoras das séries iniciais do Ensino Fundamental. Estudos Feministas, Florianópolis, v.12, n.1, p.109-129, 2004.

CARRADORE, V. M.; RIBEIRO, P. R. M. Aids, sexualidade e prevenção no espaço escolar: algumas reflexões. In: RIBEIRO, P. R. M.; FIGUEIRÓ, M. N. D. (Org.). Sexualidade, cultura e educação sexual: propostas para reflexão. São Paulo: Cultura Acadêmica; Araraquara: Laboratório Editorial FCL-UNESP, 2006. p.89-110.

SCOTT, J. Gênero: uma categoria útil para a análise histórica. Educação e Realidade, Porto Alegre, v.20, n.2, p.71-99, 1995.

SILVA, T. T. A produção social da identidade e da diferença. In: SILVA, T. T. (Org.). Identidade e diferença: a perspectiva dos estudos culturais. Petrópolis: Vozes, 2000. p.73102. 